\title{
Nanomole per Liter
}

National Cancer Institute

\section{Source}

National Cancer Institute. Nanomole per Liter. NCI Thesaurus. Code C67432.

A unit of concentration (molarity unit) equal to one billionth of a mole (10E-9 mole) of solute in one liter of solution. 